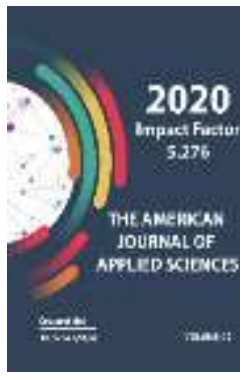

Journal Website: http://usajournalshub.c om/index,php/tajas

Copyright: Original content from this work may be used under the terms of the creative commons attributes 4.0 licence.

\section{Microbiological Assessment Of PC Consoles And Gadgets And Their Vulnerability Examples To Bactericide}

\author{
Abdullah Batu \\ Associate Professor, Department Of Biological Sciences, Faculty Of Science And Technology, \\ Beykent University, Turkey \\ Humeyra Bozbay \\ Assistant Of Department Of Biological Sciences, Faculty Of Science And Technology, Beykent \\ University, Turkey
}

\title{
ABSTRACT
}

PCs are universal and have been demonstrated to be tainted with possibly pathogenic microorganisms in certain networks. There is no practical method to test all the consoles and mouse out there, however there are good judgment approaches to forestall bacterial defilement or dispose of it on the off chance that it exists. In this investigation, swabs examples were gathered from surfaces of 250 PC consoles and mouse and plated on various microbiological media. Creatures developing on the media were cleaned and distinguished utilizing microbiological gauges. It was discovered that all the tried PC consoles and mouse gadgets, were sure for microbial pollution. Antibacterial impacts of the bactericide were additionally fixation subordinate. The agar well dissemination strategy for deciding Least Inhibitory Fixation (LIF) was utilized. The Killing rate (K) and Decimal Decrease Time (DDT) of the bactericide on the life form were additionally decided.

\section{KEYWORDS}

Microbes, Bactericide, Antibacterial Action, LIF, DDT, Murdering Rate

\section{INTRODUCTION}

$P C$ is an electronic information handling machine which acknowledges information from the outside world illuminate regarding an information and controls, figures, registers 
based on set of directions provided and put away in the memory and give the required or wanted outcomes as a yield to the client (1). In light of continuous dermal contact by various clients, microbial supplies of intrigue incorporates the PC console and mouse (2-3). Anderson and Palambo (4) archived that the normal number of microorganisms present on various client PC consoles was altogether more noteworthy than on single-client consoles.

It follows that the universal sharing of open PCs by a wide client base may encourage expanded transmission and pervasiveness of pathogenic microorganisms all through the network (7). Deficiently performed hand cleanliness and nondisinfected surfaces are two reasons why the keys and mouse-catches of workstations could be wellsprings of microbial pollution coming about thusly in aberrant transmission of possible microorganisms and nosocomial diseases.

\section{MATERIALS AND TECHNIQUES}

The assent and authorization of the digital bistros proprietors were asked so as to complete this exploration work. Along these lines, the secrecy of the data acquired from digital bistros was kept.

\section{Test Assortment And Planning}

The surfaces of 250 PC consoles and mouse of 15 digital bistros in three grounds were arbitrarily chosen for this investigation. This was performed during working hours highlighting typical understudies and staff traffic at the digital bistros. The single sterile swab stick soaked with clean saline arrangement were moved over the surfaces being tried (console and mouse). The swab sticks were promptly moved to the research facility.

\section{RESULTS}

Four microorganisms were separated in this investigation and suspected to defile PC consoles and mouse. Out of 250 examples broke down, an aggregate of 148 microbes disconnects were segregated from PC consoles and mouse. Out of which 63 Staphylococcus spp. were available; 45 of the separates were from consoles and 18 from mouse. 11 were Bacillus spp.; 8 of the confines from consoles and 3 from mouse. 47 were Escherichia spp.; 32 of the segregates from consoles and 15 from mouse. 27 were Pseudomonas spp.; 19 of the secludes from consoles and 8 from mouse.

\section{CONVERSATION}

Various investigations have demonstrated that PC consoles (and mouse) can get polluted with pathogenic microscopic organisms. In social insurance settings, it is maybe not sudden that such microorganisms would pollute these regular work surfaces. In any case, this current work indicated that microbial sullying likewise happens on PC consoles and mouse situated in an enormous college condition. An aggregate of 250 PC consoles and mouse were analyzed for bacterial pollution. The microscopic organisms segregated (Staphylococcus, Bacillus, Escherichia and Pseudomonas spp.) The tainting pace of consoles and mouse was $70.3 \%$ and $29.7 \%$, individually. It was uncovered by Hartmann et al. that the most elevated pace of defilement in patients, rooms was found on consoles. Schultz et al. found that the tried 100 consoles in 29 clinical territories for bacterial sullying, 95 from them were certain for microbial pollution.

This fortifies the chance of move of possibly pathogenic S. aureus through human hands 
which could incorporate anti-microbial safe microorganisms, for example, network related. Lifeless things have been known to assume a job in the transmission of human microbes either legitimately by surface to mouth contact or in a roundabout way by sullying of fingers and resulting hand to mouth contact . Likewise, one's palm is typically sodden to a shifting degree because of sweat, which contains sodium chloride that will support the development of halophilic microscopic organisms, for example, S. aureus. Shen who researched the bacterial tainting of PC consoles and mouse in the workplace revealed the nearness of Staphylococcus aureus, Escherichia coli and Salmonella spp. before cleansing at the accompanying recurrence 50.0, 41.7 and 8.3\%. Numerous different specialists found the nearness of Escherichia spp. on PC consoles and mouse. This connotes Escherichia spp. can likewise be separated from PC consoles and mouse at a generally high extent, which is in accordance with the consequence of this current work, Escherichia spp. (31.8\%).

The instrument of activity of disinfectant or sterile on the small scale creature continues as before regardless of the sort and is applied through the entrance into the cell and activity at the objective site(s). The last can deliver a huge impact on the practicality as the vast majority of the biocides seem to act through intra-cell instrument. The affectability or obstruction at the degree of the bacterial cell film, accordingly, can be significant factor in deciding the ultimate result of the treatment with the proposed disinfectant in the clinic practice. A portion of these bactericide likewise work by creation of damaging synthetic concoctions against different pathogenic microbes to assault layer lipids, DNA and other basic cell segments.
Checking techniques have been utilized to decide the quantity of microbial cells that endure the harmful impacts of disinfectant at different time spans for a specific period. The antimicrobial movement of the different bactericide was evaluated by performing suitable cell tallies at 20, 40, 60, 80 and $90 \mathrm{~min}$. The quantity of cells in creatures was seen to diminish step by step after an underlying slack, the span of which is an element of the centralization of the different bactericide utilized and the kind of living beings. The quantity of cells diminished quicker in Dettol ${ }^{\circledR}$, trailed by $J I K{ }^{\circledR}$ than in Isol, Purit, Izal and Septol ${ }^{\circledR}$ with negative slants. At the point when a microbial populace is exposed to the poisonous impact of an operator, the quantity of cells diminished step by step in such a way, that when the logarithm of the quantity of cell whenever when plotted against that time falls on a plummeting straight line with a negative incline.

\section{CONCLUSION}

Based on these discoveries, it is recommended that standard cleaning of consoles and mouse may help the battle against microbes in different networks. Likewise, hand washing when contact with consoles and mouse ought to fundamentally diminish the danger of defilement and cross transmission.

\section{REFERENCES}

1. Bhargav . Prologue to PCs and correspondence. Goodbye McGrawSlope Distributing Organization Constrained, New Delhi, Inida, ISBN: 124-1454322-2. 2008. P. 2. 
2. Kuehl MN, Rodriguez. Inactive enemy of per $V$ treatment ensures consumed mice against Pseudomonas aeruginosa challenge. Consumes 2007, 11: 158-165.

3. Yoon A.. PC consoles and the spread of MRSA. J. Hosp. Taint 2016, 12: 190-202.

4. Lamster IBEA. Microbial tainting of PC consoles in a college setting. Am J Taint Control 2012, 17: 307-309.

5. Nater U, Rohleder N.C, Nell M, Shrub P, Lighter $D$ and Shriners Medical clinics for Youngsters team. PC gear utilized in quiet consideration inside a multihospital framework: suggestions for cleaning and cleansing. Am J Taint Control 2007, 21(9): 413-437.

6. Chaturvedi HF. Network gained methicillin-safe Staphylococcus aureus: The study of disease transmission and potential destructiveness factors. Curr Contaminate Dis Rep 2005, 5: 559-566.

7. Humphris GM,Microbial sullying of some PC consoles and mice in National Place for Radiation Exploration and Innovation. World Appl Sci J 2004, 12(5):362-377.

8. Philipone E, Turner R, Lamster I, Brandenburg R and Rackow, K. Are PC ventilation-blowers an expected wellspring of nosocomial contaminations for patients. 2007, 52: 217-227. 